\section{What can evolutionary rescue tell us about the emergence of new resistant bacteria?}
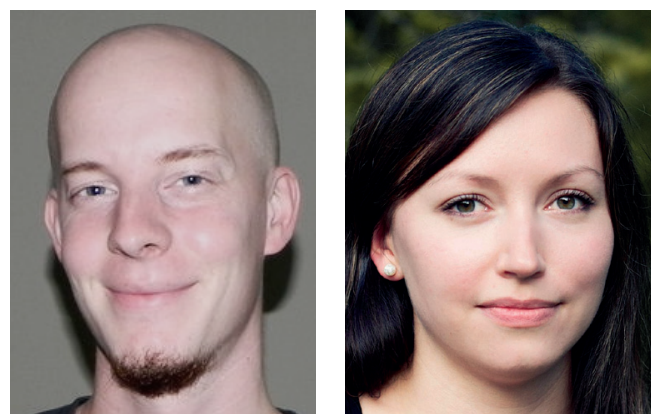

\author{
“Emergence of resistant \\ pathogens during treatment \\ due to genetic exchange \\ between bacteria is a \\ resistance evolution \\ mechanism for which \\ clinical relevance remains \\ to be resolved.”
}

Matti Jalasvuori*, \& Reetta Penttinen ${ }^{1}$

First draft submitted: 2 May 2017; Accepted for publication: 5 May 2017; Published online: 8 June 2017

Antibiotic resistance has been called as a threat to global health security. The 'easy' antibiotics have already been discovered and, to great extent, exploited to their limits. As humanity is steering toward the second era of bacterial supremacy over our means to contain them, science cannot entirely rely on discovering miracle solutions comparable to the mid-20th century penicillin. Arguably the research avenues must be broader, should we wish to develop a sustainable toolkit to fight against bacterial infections. Emergence of resistant pathogens during treatment due to genetic exchange between bacteria is a resistance evolution mechanism for which clinical relevance remains to be resolved.

Bacteria often live in communities, composed of different species and strains. Similarly, infections can be a result of multiple pathogens, and even if an infection is caused by a single agent, the pathogen may still be in contact with various other bacteria. The emergence of antibiotic resistance has been evaluated as a process where the decimating antimicrobial selects for those individuals that can tolerate its presence. Conventionally, the genetic approaches on evolution of antibiotic resistance have often focused on unveiling the molecular evolution at chromosomal level. However, when we look at the bacterial strains in hospital settings, they often carry their resistance genes in mobile elements, such as conjugative plasmids [1]. These elements readily disperse between even different bacterial species, disseminating resistances along their path.

Importantly, resistance itself can be of altruistic nature, indicating that a bacterium protects also its susceptible companions [2]. $\beta$-lactams are one of the most commonly used class of antibiotics, and, comparatively, $\beta$-lactamases that hydrolyze the ring structure of $\beta$-lactams, are very abundant among $\beta$-lactam-resistant

\section{KEYWORDS}

- antibiotic resistance $\bullet$ conjugative plasmids $\bullet$ evolutionary rescue - horizontal gene transfer $\bullet$ phage therapy 
“...it is possible that in some cases the bacterial pathogen causing an infection may not be resistant to antibiotics, but it is under strong antibiotic selection when the plasmid from commensal flora restores the positive growth of originally susceptible bacteria." bacteria. A $\beta$-lactamase-producing bacterium inactivates the drug for all bacteria in its vicinity [2]. This altruistic nature poses a potential problem from therapeutic perspective as, not only do the bacteria help others, but it also provides the susceptible pathogen enough time to acquire the resistance genes via horizontal gene transfer [3]. Various conjugative plasmids from different extended-spectrum $\beta$-lactamase (ESBL)-producing Escherichia coli strains are able to evolutionary rescue other bacteria in high $\beta$-lactam concentrations [4].

ESBL carriage refers to asymptomatic carrier state of ESBL-producing bacteria in the gut. The prevalence of ESBL carriage has increased globally during the last decade and is no longer limited to healthcare settings. Notably, ESBL carriage among the community has become more frequent and is typically associated with international travel (but not necessarily with hospitalization) [5]. Though ESBL carriage itself is rarely dangerous and the carriers can be cured of resistance plasmids spontaneously [6], it increases ESBL transmission and may thereby compromise the effectiveness of future antibiotic therapies [7]. Given the resistance genes are often located in conjugative plasmids, they may be mobilized also within the local gut flora. Indeed, ecological proximity rather than genetic relatedness appears to be a more relevant factor in horizontal gene transfer [8].

Krol et al. measured the efficiency of various resistance plasmids to invade $E$. coli biofilms [9] . Although biofilms are generally more resistant to antimicrobials even without specific resistance genes, the altruistic nature of $\beta$-lactamases suggests that under antibiotic selection, planktonic bacteria can increase the overall resistance of a biofilm even further. Krol et al. noted a million-fold difference in biofilm invasiveness for different plasmids, indicating that the presence of certain mobile elements in commensal bacteria can have much greater effect on improving biofilm survivability. As far as we know, the exchange of resistance plasmids during treatment has not been studied. Hence, it is possible that in some cases the bacterial pathogen causing an infection may not be resistant to antibiotics, but it is under strong antibiotic selection when the plasmid from commensal flora restores the positive growth of originally susceptible bacteria.

The plasmids of enterobacterial pathogens have been identified in numerous studies [1]. Although plasmids differ between strains, genuinely novel plasmid types are rarely identified. Hence, when attempting to evaluate risks in terms of horizontal gene transfer during treatment, the plasmid diversity is not uncontrollably large. This enables a specific, case-bycase risk analysis without a need for an extensive study of the particular plasmids in each patient. However, there is still much research to be done in order to link different plasmid profiles to the eco-evolutionary risks during treatment. Namely, the species and strain-specific localization of ESBL plasmids in the flora could be determined at the time of hospitalization of ESBL-positive patients, and, should they develop a resistant infection, the potential horizontal rescue events could be determined. Yet, the hospital-borne pathogens are often already resistant to $\beta$-lactams, thus it is possible that community-associated infections that are treated with antibiotics may form a more likely setting for evolutionary rescue via horizontal transfer to take place. Naturally, such events would be notoriously difficult to be traced afterward, but given the advances in sequencing and diagnostic tools, the beforehand plasmid-host profile could be determined for risk group patients (such as people with immunodeficiency or diabetes) who are more likely to develop a resistant infection afterward. Also, anthropological actions in agriculture and medicine disseminate antibiotics to natural environments, thus both maintaining the existence and facilitating the spread of resistance plasmids [10].

It is possible to prevent horizontal gene transfer, at least in vitro. Conjugative plasmiddependent bacteriophages (viruses that infect bacteria) attach to plasmid-encoded features on a bacterial cell surface. These phages rapidly select for bacteria that have either lost their resistance plasmids (thus making them susceptible to antibiotics) or that no longer contain the plasmid-encoded features on the cell surface (thus being incapable of conjugation) [11,12]. These phages quite efficiently prevent the exchange of plasmids even in the presence of antibiotics that particularly favor their horizontal movement between hosts [13]. Further, certain pilus-binding proteins from phages provide a physical barrier blocking pilus-mediated transfer of plasmids between hosts [14]. However, phages or phage proteins do not provide a miracle solution to all possible evolutionary rescue scenarios since these agents are rather specific to certain types of plasmids 
(or more accurately, conjugation mechanisms). Yet, more extensive sampling of phage sphere might help discover viruses against most conjugation mechanisms. Isolation protocols that especially select for plasmid-dependent phages have been developed [15] and could probably be even further adjusted for plasmids commonly circulating among pathogens.

In the future, retaining the efficacy of current and future antibiotics will require us to take into account the whole picture in the resistance evolution. This also calls for more thorough understanding of the role of horizontal gene transfer in environmental bacterial populations as well as in gut and infection sites, all of which are potential locations where new genetic combinations may emerge in response to antibiotics.

\section{Acknowledgements}

Photo of $R$ Penttinen was taken by $P$ Tsukayama.

\section{Financial \& competing interests disclosure}

The authors kindly acknowledge funding from the Academy of Finland (grants 252411 and 297049). The authors have no other relevant affiliations or financial involvement with any organization or entity with a financial interest in or financial conflict with the subject matter or materials discussed in the manuscript apart from those disclosed.

No writing assistance was utilized in the production of this manuscript.

\section{References}

1 Brolund A, Franzen O, Melefors O, Tegmark-Wisell K, Sandegren L. Plasmidome-analysis of ESBL-producing Escherichia coli using conventional typing and high-throughput sequencing. PLoS ONE 8(6), e65793 (2013).

2 Yurtsev EA, Chao HX, Datta MS, Artemova T, Gore J. Bacterial cheating drives the population dynamics of cooperative antibiotic resistance plasmids. Mol. Syst. Biol. 9, 683 (2013).

3 Ojala V, Mattila S, Hoikkala V, Bamford JKH, Jalasvuori M. Evolutionary rescue of bacteria via horizontal gene transfer under a lethal beta-lactam concentration. J. Glob. Antimicrob. Resist. 2(3), 198-200 (2014).

4 Mattila S, Ruotsalainen P, Ojala V, Tuononen T, Hiltunen T, Jalasvuori M. Conjugative ESBL plasmids differ in their potential to rescue susceptible bacteria via horizontal gene transfer in lethal antibiotic concentrations. J. Antibiot. (Tokyo) 70 (6), 805-808 (2017).

5 Hassing RJ, Alsma J, Arcilla MS, van Genderen PJ, Stricker BH, Verbon A. International travel and acquisition of multidrug-resistant Enterobacteriaceae: a systematic review. Euro. Surveill. 20(47), 30-43 (2015).

6 Titelman E, Hasan CM, Iversen A et al. Faecal carriage of extended-spectrum $\beta$-lactamase-producing Enterobacteriaceae is common 12 months after infection and is related to strain factors. Clin. Microbiol. Infect. 20(8), O508-O515 (2014).

7 Tumbarello M, Sali M, Trecarichi EM et al. Bloodstream infections caused by extendedspectrum- $\beta$-lactamase-producing Escherichia coli: risk factors for inadequate initial antimicrobial therapy. Antimicrob. Agents Chemother. 52(9), 3244-3252 (2008).

8 Smillie CS, Smith MB, Friedman J, Cordero OX, David LA, Alm EJ. Ecology drives a global network of gene exchange connecting the human microbiome. Nature 480 (7376), 241-244 (2011).

9 Krol JE, Wojtowicz AJ, Rogers LM et al. Invasion of $E$. coli biofilms by antibiotic resistance plasmids. Plasmid 70 (1), 110-119 (2013).

10 Andersson DI, Hughes D. Evolution of antibiotic resistance at non-lethal drug concentrations. Drug Resist. Updat. 15(3), 162-172 (2012).
11 Jalasvuori M, Friman V, Nieminen A, Bamford JKH, Buckling A. Bacteriophage selection against a plasmid-encoded sex apparatus leads to the loss of antibioticresistance plasmids. Biol. Lett. 7(6), 902-905 (2011).

12 Ojala V, Mattila S, Hoikkala V, Bamford JKH, Hiltunen T, Jalasvuori M. Scoping the effectiveness and evolutionary obstacles in using plasmid-dependent phages to fight antibiotic resistance. Future Microbiol. 11(8), 999-1009 (2016).

13 Ojala V, Laitalainen J, Jalasvuori M. Fight evolution with evolution: plasmid-dependent phages with a wide host range prevent the spread of antibiotic resistance. Evol. Appl. 6(6), 925-932 (2013).

14 Lin A, Jimenez J, Derr J et al. Inhibition of bacterial conjugation by phage M13 and its protein $\mathrm{g} 3 \mathrm{p}$ : quantitative analysis and model. PLoS ONE 6(5), e19991 (2011).

15 Nuttall D, Maher D, Colleran E. A method for the direct isolation of inch plasmiddependent bacteriophages. Lett. Appl. Microbiol. 5(2), 37-40 (1987). 